\title{
Use of Cylindrical Bristle Clusters as a novel multispecies fish pass to facilitate upstream movement at gauging weirs
}

\author{
Daniella Montali-Ashworth*a ${ }^{*}$ Andrew S. Vowles*a ${ }^{*}$ Gustavo de Almeida ${ }^{\mathrm{b}}$, and Paul S. Kemp ${ }^{\mathrm{a}}$
}

${ }^{\mathrm{a}}$ The International Centre for Ecohydraulics Research, School of Engineering, Faculty of Engineering and Physical Sciences, University of Southampton, UK, SO16 7QF

${ }^{b}$ Water and Environmental Engineering Group, School of Engineering, Faculty of Engineering and Physical Sciences, University of Southampton, UK, SO16 7QF

E-mail addresses: D.Montali-Ashworth@soton.ac.uk; asv104@soton.ac.uk; p.kemp@soton.ac.uk; g.deAlmeida@soton.ac.uk

*Author to whom correspondence should be addressed: Tel: +44 02380 592700. Fax: +44 2380 593166. E-mail address: D.Montali-Ashworth@soton.ac.uk; asv104@soton.ac.uk

\section{Abstract}

Globally, gauging weirs are commonly installed in rivers to monitor flows. They have widespread negative impacts on the upstream movement of fish due to the barriers created by the unfavourable hydraulic conditions on the downstream face. There is a need to develop simple low-cost solutions to enhance multi-species fish passage, while not impacting the ability of these structures to gauge flow or increasing their potential to accumulate debris. This study investigated the use of an array of Cylindrical Bristle Clusters (CBCs), mounted on the downstream face of Crump weirs, to improve upstream passage of multiple species of fish while maintaining gauging accuracy. The simplicity and modularity of the design helps improve cost effectiveness and ease of installation. Laboratory tests with roach (Rutilus rutilus) showed that the passage efficiency of a Crump weir was increased from $0 \%$ (control) to $\approx 30 \%$ when retrofitted with CBCs. Swim path analysis indicated fish utilised low velocity zones in the wake of clusters to facilitate passage. Time taken to pass the weir and length of the swim path were greatest under the highest cluster density, where manoeuvrability was most constrained. Following these promising experimental results, the fish pass efficiency of a weir retrofitted with a staggered array of $\mathrm{CBCs}$, was evaluated in the field. Upstream passage of a number of nonsalmonid fish, including chub (Squalius cephalus) and roach, was monitored using Passive Integrated Transponder telemetry at a $7 \mathrm{~m}$ long, $1.2 \mathrm{~m}$ wide, Crump weir with a 1:5 downstream slope. Overall passage efficiency, considering all species, increased from $2 \%$ to $14 \%$ when the fish pass was installed, and for chub from 0 to $52 \%$. Debris accumulation was minimal during the test period. Assessment of the impact of a variety of $\mathrm{CBC}$ array densities on gauging was also undertaken. As predicted using theory, there was no effect on gauging when arrays were placed downstream of the point at which flow regime changes from sub- to supercritical. This study highlights the potential for a staggered array of $\mathrm{CBCs}$ to improve the upstream passage of multiple species of fish at gauging weirs, common barriers to fish migration throughout the world, without affecting the accuracy of flow gauging.

\section{Keywords}

Cylindrical bristle cluster; Roach; Chub; Field installation; Habitat connectivity; Fish passage 


\section{Introduction}

Fluvial habitat connectivity is essential for the transfer of energy, materials and organisms along rivers (Pringle, 2001). In-river barriers, such as dams and weirs, disrupt the river continuum which is one of the principal explanations for why rivers are considered among the most threatened and degraded of all the worlds ecosystems (Vörösmarty et al., 2010). From a fisheries perspective, the impact of river barriers is critical for those that depend on them, as numerous fish populations have declined, and in some cases have been extirpated as movement between critical habitats is impeded (Lucas and Baras, 2001; Dibley et al., 2012). While the impact of large-scale structures, such as some hydropower dams, has gained much interest (Larinier, 2001), small-scale infrastructure is often overlooked. However, in many countries their impacts are substantial because of their high density that reflects a long historic legacy of river development.

Gauging weirs are small structures commonly installed to measure river discharge and are essential for flood monitoring and river management practices (Armstrong et al., 2010; Rickard et al., 2003; Wessels and Rooseboom, 2009; Larinier, 2001). Long-term records of river flow data from gauging weirs enable, for example, the analysis of the potential effects of climate change on river flows, accounting water use for irrigation and abstraction purposes, and informing flood prediction and prevention strategies. Gauging weirs, such as the flat- $\mathrm{V}$ and Crump design, are commonly employed internationally. They span the width of the channels in which they are installed and have a triangular longitudinal profile with either a central convergence (flat-V) or a uniform distribution of flow along the crest (Crump). As with many low-head barriers, these gauging weirs can limit upstream fish passage as they produce a combination of high velocity and shallow water depths over the weir face. Passage is limited if there is insufficient depth for fish to attain adequate swimming propulsion over the face, or if the velocities experienced exceed burst swimming capabilities (e.g. Vowles et al., 2015; Kerr et al., 2015; Lucas and Frear, 1997). Therefore, with increasing river development, there is a requirement to develop efficient methods to mitigate environmental impacts created by these structures.

The impacts of gauging weirs on fish passage has been investigated in relation to several species, including the diadromous anguilliform river lamprey (Lampetra fluviatilis) (Russon et al., 2011) and European eel (Anguilla anguilla) (Vowles et al., 2017), and potamodromous fishes, such as barbel (Barbus barbus) and grayling (Thymallus thymallus) (Lucas and Frear, 1997; Lucas and Bubb, 2005). Such studies indicate that gauging weirs can substantially impede the movement of fish, and ultimately impact population viability over the long-term. Provision of fish passage at gauging weirs can help re-establish habitat connectivity (Dodd et al., 2018), and examples of designs used include a 'Low Cost Baffle' (LCB) pass (Servais, 2006) and 'tiles' (Tummers et al., 2018). The LCB pass is made up of rectangular baffles that are mounted onto the downstream weir face in stepped rows parallel to the crest and arranged so that water is funnelled through a central V shaped channel. The baffles reduce water velocity and increase depth and are intended to facilitate upstream passage without reducing the gauging capabilities of the weir, or increasing the potential to accumulate debris. Unfortunately, failure to 
meet both of these design criteria is observed under experimental and field settings if the baffles are placed too close to the crest. To improve gauging, the baffle must be placed at such a distance from the crest that fish passage can be compromised (Servais, 2006). Alternatively, 'tiles' of a variety of designs, such as those with projections of bristles, solid cylinders, or conical shaped studs, are installed on the weir face to increase roughness and facilitate the upstream movement of fish that are able to climb or swim through them. These low-cost fish passage solutions are typically designed to help the passage of eel, and to a lesser extent lamprey, and have achieved varying degrees of success (Armstrong et al., 2010; Kerr et al., 2015; Vowles et al., 2017; Watz et al., 2019). They are considered to be species-specific, providing a climbing substrate for eel, but are likely to be ineffective for other species that do not have an anguilliform body morphology or exhibit climbing behaviour.

A logical extension of the development of tiles is to broaden the design remit to include a wider range of target species. Here we propose the adaptation of tiles through incorporating Cylindrical Bristle Clusters (CBCs) arranged in a staggered array to facilitate upstream movement of fish, and potentially other aquatic organisms. In an advance of the solid cylindrical design commonly used (Baker and Boubée, 2006; Vowles et al., 2017), which provide heterogeneity of flow as a result of the wakes created (Kerr et al., 2016), CBCs were used in this study as their higher porosity ensures the wakes are longer (Nicolle, 2009) and drag is greater (Taddei et al., 2016). When applied to fish passes, $\mathrm{CBCs}$ can result in lower impedance of flow than other designs, reducing impacts on gauging, increasing space available for fish to swim while still reducing water velocity and increasing depth. The staggered arrangement was chosen because, for the same density, the greatest flow resistance is created compared to other arrangements (Wang et al., 2013).

In this study, the potential to enhance the upstream fish passage efficiency of Crump weirs was investigated for multiple species through the installation of CBCs on the downstream face. Such an approach is appealing as it represents a low-cost fish passage solution that can be easily applied retrospectively as part of an adaptive river management strategy. To achieve this aim we attempted to determine: 1) whether a staggered array of clusters improves passage of a cyprinid-, the roach (Rutilus rutilus), when compared with the performance of a control (unmodified) weir under experimental settings; 2) the influence of different CBC spacings on the movement of fish in a flume; 3) if passage efficiency is replicated in the field for multiple species without accumulating excessive debris; and 4) the effect of CBC array configurations on gauging. Recommendations are provided for gauging weir retrofit and optimisation of design efficiency that will be of value to regulatory agencies, ecological engineers, and the operators and managers of river infrastructure tasked with provisioning services while improving ecological status and environmental sustainability. Due to the widespread global distribution of gauging weirs and similar low head barriers, this low cost fish passage design is likely to have significant impact in reconnecting fragmented fluvial habitats in an effort to restore degraded freshwater ecosystems. 


\section{Materials and methods}

\subsection{Laboratory fish passage trials}

Experiments were conducted using a model Crump weir installed in a trapezoidal open channel flume (60 m long, $2.1 \mathrm{~m}$ and $3 \mathrm{~m}$ wide at the base and top, respectively, and $0.5 \mathrm{~m} \mathrm{deep}$ ) at the International Centre for Ecohydraulics Research (ICER) Laboratory, Chilworth Science Park, University of Southampton (UK). Inside the trapezoidal flume a rectangular channel (1.36 $\mathrm{m}$ wide and $9 \mathrm{~m}$ long) was constructed and into which the weir was placed (Fig. 1). The channel entrance was tapered to avoid flow separation.

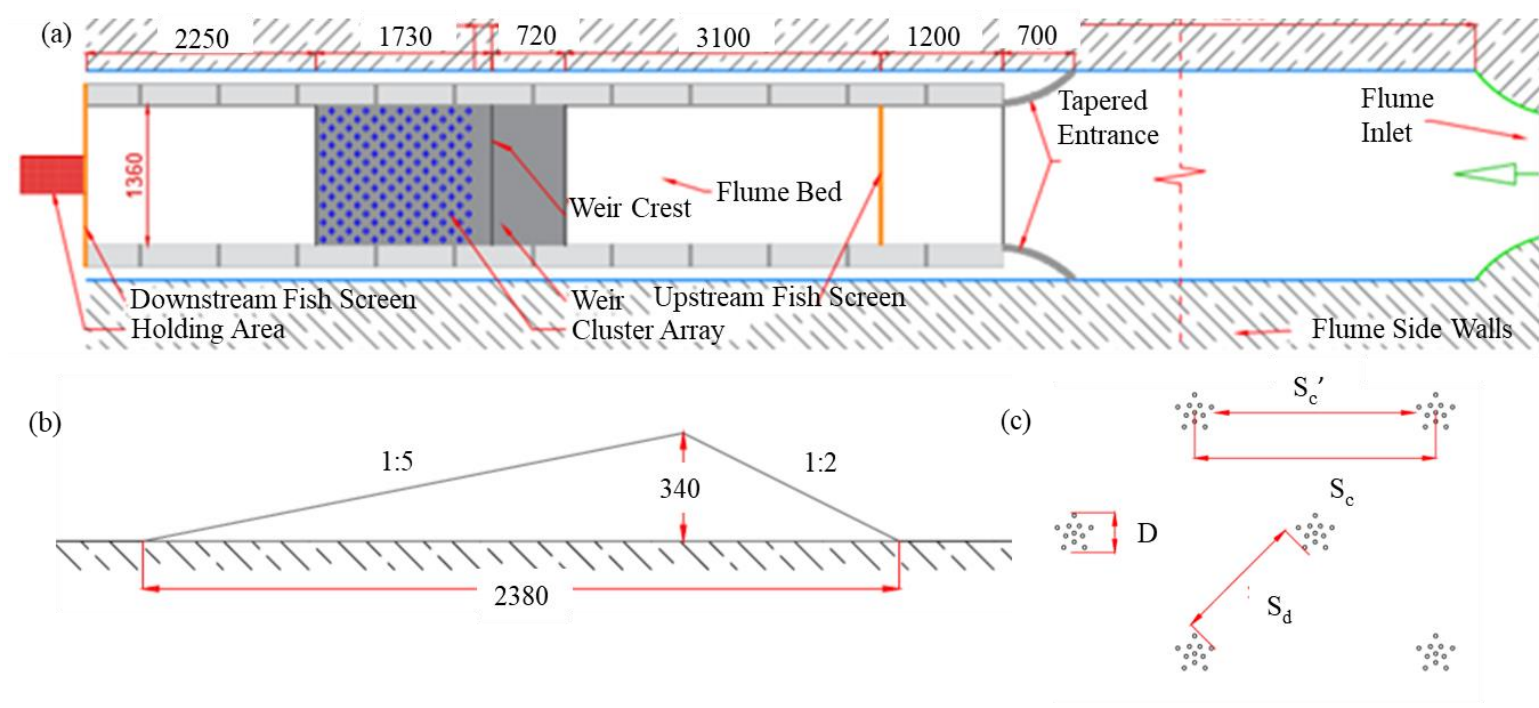

Fig.1 (a) Plan of the experimental setup used to conduct fish passage trials indicating location of the weir and fish release (holding) area, (b) weir cross-section indicating dimensions, and (c) cluster metrics (diameter [D] and diagonal and horizontal spacing between the outer edges of the clusters and horizontally from centre to centre [Sd, $S c^{\prime}$ and $\left.S c\right]$, respectively) which were altered to test their influence on fish passage. All units are in mm.

Trials were undertaken with (treatment) and without (control) CBCs. Cylindrical bristles, made from Polybutylene terephthalate (Cottam Brush, UK), were used to create the clusters. The material properties were expected to reduce the probability of permanent deformation induced by water and debris loading. When installed, the staggered array of cylindrical clusters covered the entirety of the downstream weir face $\left(2 \mathrm{~m}^{2}\right)$ with the exception of $0.17 \mathrm{~m}$ between the weir crest and the first line of CBCs (Fig. 1). This gap was included in the design to allow the flow to transition from sub- to supercritical before encountering the first line of clusters. The region of supercritical flow ensures that the increased depths produced by the CBC will not drown the weir, ensuring that gauging accuracy is unaffected. In addition to the control (subsequently referred to as $\lambda \mathrm{a}$ ), three different treatments were tested which consisted of minimum spacing between clusters $\left(\mathrm{S}_{\mathrm{d}}\right.$; Fig. 1) of $0.06,0.1$ and $0.15 \mathrm{~m}$ (subsequently referred to as $\lambda \mathrm{b}, \lambda \mathrm{c}$ and $\lambda \mathrm{d}$, respectively). Spacings were selected based on UK 
National Guidelines for the width required between baffles to allow small ( $0.10-0.14 \mathrm{~m}$ fish length), medium $(0.14-0.17 \mathrm{~m})$ and large ( $>0.17 \mathrm{~m})$ fish to ascend baffled fishways (Armstrong et al., 2010).

A CBC diameter of $0.03 \mathrm{~m}$ was tested to create a series of low velocity zones extending from behind one cluster to the next (Nicolle, 2009). The bristles within the clusters were equally spaced and resulted in a density $(\varphi)$ of 0.1 (defined as $N_{c} d^{2} / D^{2}$, where $N_{c}$ is the number of elements within the cluster, $d$ is the internal diameter of individual bristle elements and $D$ is the cluster diameter) where the wake is longest without creating recirculation behind the cluster (Taddei et al., 2016). A bristle height of $0.1 \mathrm{~m}$ was used as this was greater than the fish body depth.

An upward looking Acoustic Doppler Current Profiler (ADCP) (Sontek IQ, San Diego, CA, USA) placed on the bottom of the flume $6 \mathrm{~m}$ upstream of the weir was used to measure flow rate and water depths. An average flow of $0.08 \mathrm{~m}^{3} \mathrm{~s}^{-1}$ was used for all treatments, with upstream water depths of $0.4 \mathrm{~m}$ recorded. This translates into a discharge per unit width $(q)$ of $0.06 \mathrm{~m}^{2} \mathrm{~s}^{-1}$. Mean \pm SD temperature recorded during the trials was $15.1 \pm 0.9^{\circ} \mathrm{C}$. Time averaged velocities and depths on the weir face were measured at the crest, $0.075 \mathrm{~m}$ from the crest, and every $0.1 \mathrm{~m}$ from this point to the base of the weir using a velocimeter (Valeport Model 801) and point gauge, respectively. During each treatment, measurements were recorded in between the CBCs, and not in the wakes of the clusters. Mean $\pm \mathrm{SD}$ and maximum velocities down the weir face (time and space averaged over the length of the weir) were respectively $1.86 \pm 0.53$ and $2.5 \mathrm{~m} \mathrm{~s}^{-1}$ for $\lambda \mathrm{a}, 1.38 \pm 0.26$ and $1.7 \mathrm{~m} \mathrm{~s}^{-1}$ for $\lambda \mathrm{b}, 1.66 \pm 0.38$ and $2.1 \mathrm{~m} \mathrm{~s}^{-1}$ for $\lambda \mathrm{c}$, and $1.74 \pm 0.4$ and $2.2 \mathrm{~m} \mathrm{~s}^{-1}$ for $\lambda \mathrm{d}$. Reynolds numbers around the clusters, calculated using the water velocity and depth at each point on the weir face, ranged from $6 \times 10^{4}-1.2 \times 10^{5}$.

Roach were chosen as the model species due to their widespread UK distribution and burst swim speeds that are representative of other potamodromous non-salmonids (Clough and Turnpenny, 2001). Trials were conducted using individual fish sourced from a lake in Caddington (Bedfordshire, UK) 3 weeks prior to experimentation. Fish were kept in $1200 \mathrm{~L}$ holding tanks $\left(15.0^{\circ} \mathrm{C} \pm 7.4\right)$ where water quality (ammonia, nitrite, nitrate) was monitored and maintained within suitable levels for fish health (nitrite $<1 \mathrm{~m} \mathrm{~L}^{-1}$ and nitrate $<50 \mathrm{mg} \mathrm{L}^{-1}$ ) through daily part (typically 50\%) exchange with dechlorinated water. Sixty trials where conducted for each treatment and the control (mean length $(\mathrm{m}) \pm \mathrm{SD}(\mathrm{m}) \lambda \mathrm{a}: 0.16 \pm 0.04, \lambda \mathrm{b}$ : $0.16 \pm 0.36, \lambda \mathrm{c}: 0.16 \pm 0.03, \lambda \mathrm{d}$ : $0.15 \pm 0.03$ ) over a period of 2 weeks (14th May 2016 - 31st May 2016) between dawn (4 am) and dusk (10 pm).

Acclimatisation to the flume water temperature occurred for at least $1 \mathrm{~h}$ prior to the start of each trial. Fish were held in a perforated barrel placed downstream of the experimental area, defined by two wire mesh screens placed approximately $2 \mathrm{~m}$ downstream of the weir base and $2 \mathrm{~m}$ upstream of the weir crest. On initiation of each trial a single fish was released at the furthest downstream extent of the experimental area (approximately $2 \mathrm{~m}$ downstream of the foot of the weir). Each trial lasted until the fish successfully ascended over the weir crest or 
after $30 \mathrm{~min}$ had elapsed. Time of attempt, when a fish entered onto the downstream weir face, and time of successful passage, when the whole body of a fish passes over the weir crest, were documented during trials. Fish swim paths were recorded using videography (30 frames per second) and post processed using tracking software (Logger Pro v3.8.2, Vernier Software, Beaverton, OR, USA) that recorded head position in each video frame. Two-dimensional $(\mathrm{x}, \mathrm{y})$ co-ordinates were produced and subsequently used to calculate the swim path length (i.e. distance travelled on the downstream weir face as fish ascended upstream) and time taken to pass the weir.

Passage efficiency was calculated for each treatment as the number of fish that passed the weir as a percentage of those that attempted. A chi-square test was used to test for a difference in passage efficiency between treatments. As data relating to swim path length and time to pass was non-parametric (Shapiro-Wilk test), Kruskal-Wallis tests were used to determine whether the metrics differed with treatment. Dunn tests were carried out post hoc to determine where significant differences occurred between treatments.

\subsection{Field fish passage validation and debris monitoring}

To validate effectiveness under a field scenario, the CBC bristle pass was installed on a compound Crump weir at Shermanbury Place Estate on the River Adur, West Sussex, UK (50 $\left.95^{\prime} 74.63^{\prime \prime} \mathrm{N}, 0^{\circ} 26^{\prime} 58.75^{\prime \prime} \mathrm{W}\right)$ (Fig. 2). The weir has a central channel ( $1.2 \mathrm{~m}$ wide and $7 \mathrm{~m}$ long) and two channels on either side (both $2 \mathrm{~m}$ wide). The central weir crest is $0.45 \mathrm{~m}$ lower than those at the side, which only overflow during high flow events $>2.75 \mathrm{~m}^{3} \mathrm{~s}^{-1}$. This weir was selected for the tests as the fish community is dominated by non-salmonids, particularly roach and chub (Squalius cephalus), and is known to present a barrier to fish movement (Environment Agency Pers. Comm.).

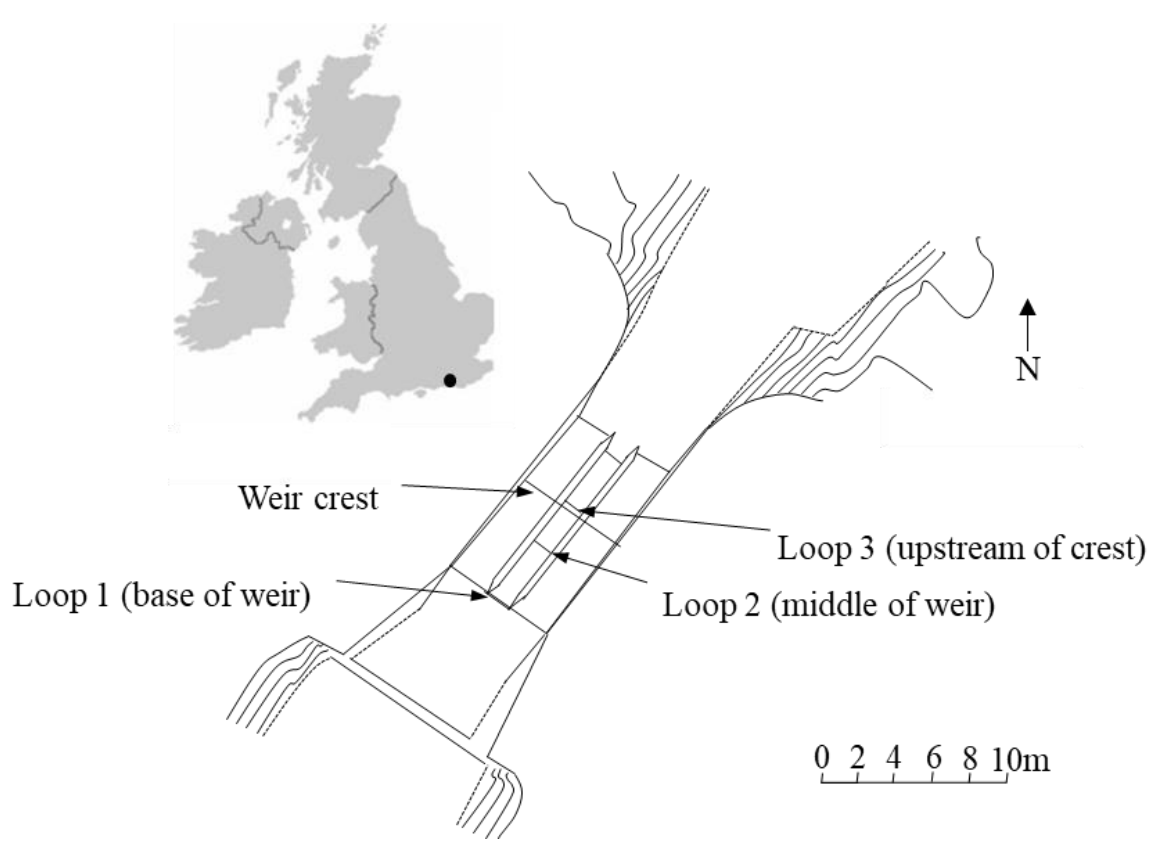

Fig.2 Site location (black dot on inset map) and plan of the compound Crump weir on the River Adur, West Sussex, UK $\left(50^{\circ} 95^{\prime} 74.63^{\prime \prime} \mathrm{N}, 0^{\circ} 26^{\prime} 58.75^{\prime \prime} \mathrm{W}\right)(\mathrm{EA}, 2017)$ on which a novel fish pass was installed. The 
fish pass consisted of Cylindrical Bristle Clusters mounted onto the downstream weir face in the central channel. Positions of PIT loops 1, 2 and 3 and the weir crest are indicated.

The bristle pass comprised of a staggered array of CBCs spaced a minimum of $0.17 \mathrm{~m}$ apart with a diameter of $0.05 \mathrm{~m}$, height of $0.15 \mathrm{~m}$, and cluster density of 0.05 . Compared to the flume studies, a larger spacing and diameter was tested in the field to facilitate passage of larger fish and increase the area of low velocity behind the clusters. The pass was installed $0.2 \mathrm{~m}$ below the weir crest to minimise any backwater effect created.

Passive Integrated Transponder (PIT) telemetry was used to quantify fish passage performance at the weir. Three rectangular PIT loops were installed; the first at the base of the weir adjacent to the wing-walls, the second on the weir face $3 \mathrm{~m}$ upstream from the base, and the third $0.3 \mathrm{~m}$ upstream of the weir crest (Fig. 2). The loops were connected to tuning boxes linked to multiplex Half Duplex readers (Wyre Microdesign, UK) and data loggers housed securely on the river bank and powered by three $110 \mathrm{aH}$ leisure batteries connected in series.

The detection range was measured by passing PIT tags of $12 \mathrm{~mm}$ and $23 \mathrm{~mm}$ through the PIT loops. Tags were secured to a pole and moved towards the centre, left and right of the loops at different angles while the reader was monitored to determine at what distance/position the tag was detected. At all loops, the detection range was $0.2 \mathrm{~m}$ and $0.3 \mathrm{~m}$ for $12 \mathrm{~mm}$ and $23 \mathrm{~mm}$ tags, respectively. The detection range for $32 \mathrm{~mm}$ tags was assumed to be $>0.3 \mathrm{~m}$. Detection efficiency was quantified as the quotient of the number of times the PIT tag was detected and the number of times the PIT tag was passed through the loop $(n=100)$. Detection efficiency at a discharge of $0.6 \mathrm{~m}^{3} \mathrm{~s}^{-1}$ was $100 \%$.

River water temperature was recorded every hour using multiple submerged temperature loggers (Hobo Temp/Light Pendant, Onset Computer Corporation, MA, USA) attached to each PIT loop. Multiple loggers were deployed in case of equipment failure or loss. Discharge data was monitored every 15 min by the Environment Agency.

Fish passage was monitored at the weir with (treatment) and without (control) the bristle pass installed during the months of April, May and June 2017. Control and treatments were tested for approximately half of each month ( Table 1). Electrofishing (pulsed DC with a single anode) was conducted from a boat over an approximately $300 \mathrm{~m}$ stretch of river upstream and downstream of the weir. Captured fish were anaesthetised $\left(0.3 \mathrm{ml} \mathrm{L}^{-1} 2-\right.$ phenoxyethanol), identified to species, measured (fork length, with the exception of eel which were measured as total length) and weighed. A $12 \mathrm{~mm}, 23 \mathrm{~mm}$ or $32 \mathrm{~mm}$ HDX PIT tag (Wyre Micro) was inserted into the peritoneal cavity (tag burden was $<2 \%$ of fish mass). Tags were sterilised in ethanol, rinsed in purified water and inserted through a $5 \mathrm{~mm}$ ventral incision. Once fish had recovered in aerated river water they were released in a low velocity area downstream of the weir, approximately $10 \mathrm{~m}$ below loop 1 . 
Table 1 Periods $(\mathrm{C}=$ control, $\mathrm{T}=$ treatment $)$ over which multispecies fish passage over a Crump gauging weir on the River Adur, West Sussex, UK $\left(50^{\circ} 95^{\prime} 74.63^{\prime \prime} \mathrm{N}, 0^{\circ} 26^{\prime} 58.75^{\prime \prime} \mathrm{W}\right)$ was monitored. Dates and the number of fish tagged during each tagging event are provided.

\begin{tabular}{|c|c|c|c|}
\hline Treatment & Date (2017) & Tagging & Number tagged \\
\hline C1 & 27th March - 12th April & 27th March & 163 \\
\hline $\mathbf{T 1}$ & 13th April - 26th April & & \\
\hline $\mathrm{C2}$ & 27th April - 15th May & & \\
\hline $\mathbf{T} 2$ & 16th May - 31st May & 16th May & 127 \\
\hline C3 & 31st May - 14th June & & \\
\hline $\mathbf{T 3}$ & 14th June - 3rd July & & \\
\hline
\end{tabular}

Fish passage performance was monitored for chub $(-n=70$, mean \pm SD length $=0.274 \pm 0.133$ m: $)$, dace (Leuciscus leuciscus) $(n=22$, length $=0.151 \pm 0.220 \mathrm{~m})$, roach $(n=124$, length $=0.124 \pm 0.230 \mathrm{~m})$, gudgeon (Gobio gobio) $(n=6$, length $=0.113 \pm 0.063 \mathrm{~m})$, pike (Esox lucius) $(n=16$, length $=0.392 \pm 0.151 \mathrm{~m})$, bream (Abramis brama) $(n=15$, length $=0.369 \pm 0.121 \mathrm{~m})$, brown trout $($ Salmo trutta $)(n=3$, length $=0.192 \pm 0.013 \mathrm{~m})$, rudd (Scardinius erythrophthalmus) $(n=5$, length $=0.134 \pm 0.020 \mathrm{~m})$, perch (Perca fluviatilis) $(n=17$, length $=0.174 \pm 0.058 \mathrm{~m})$ and eel (Anguilla anguilla $)(\mathrm{n}=12$, length $=0.489 \pm 0.225 \mathrm{~mm})$. Detections at loops 1 , 2 and 3 determined the number of fish that attempted to ascend the weir, those able to ascend half the weir face, and the number that successfully passed, respectively. Attraction efficiency was defined as the number of fish detected at the foot of the weir (loop 1), and assumed to be attempting to ascend, as a percentage of those tagged and released downstream. Passage efficiency was defined as the number of fish that successfully ascended the fish pass (detected at loop 3) as a percentage of those that attempted (detected at loop 1).

To determine factors influencing fish passage, further analysis was conducted on data collected for chub, the only species for which a sufficiently large data set was obtained. A binomial regression model was created to identify whether pass installation, flow, temperature, time of day, number of days since tagging, change in flow per unit of time (15 min), fish length and/or weight were predictors of successful passage. The most parsimonious model was determined by AIC value comparison. The time variant predictors (as opposed to length or weight) used in the model were those collected nearest to the time at which the fish was last detected at loop 1 (i.e. attempting to pass, which may or may not have been successful). Observations remained "independent" of one another, avoiding violation of the assumptions required for statistical analysis i.e. "repeat measures" as the last attempt (if not successful) or the attempt immediately prior to the first successful passage was included, irrespective of treatment. Passage success was assumed when the fish was subsequently detected at loop 3 within 30 mins of 
detection at loop 1 or 2 . Fish that were detected at loop 3 without being recently detected at loop 1 or 2 were not counted as having passed, as during periods of high flow an alternative route was available. Debris accumulation within the fish pass was monitored using a wireless camera (Ltl Acorn Ltl-6210 M) and periodically by Environment Agency operational staff (April 2017 - April 2018).

\subsection{Effect on gauging}

Gauging experiments were undertaken in a rectangular open channel flume $(13 \mathrm{~m}$ long, $0.6 \mathrm{~m}$ wide and $0.8 \mathrm{~m}$ deep) at the ICER Ecohydraulics Laboratory, Boldrewood Innovation Campus, University of Southampton (UK). Analysis of the effect of three arrangements of spacing and diameter $(0.07 \mathrm{~m}$ diameter with $0.1[\lambda \mathrm{A}]$ and 0.15 $[\lambda \mathrm{B}] \mathrm{m}$ diagonal spacing, and $0.05 \mathrm{~m}$ diameter with $0.15 \mathrm{~m}$ diagonal spacing $[\lambda \mathrm{C}])$ on gauging at a Crump weir with 1:5 downstream slope, 1:2 upstream slope, and $0.4 \mathrm{~m}$ crest height was undertaken for free-flowing conditions (hydraulic jump present downstream of the array). Control measurements of water depth (C) were taken using a point gauge $2 \mathrm{~h}_{\max }$ upstream of the weir crest (approx. $0.3 \mathrm{~m}$, as for BS ISO 2043602008 (2008) where $\mathrm{h}_{\max }$ is the maximum gauged head relative to the crest level), at the weir crest, and $1 \mathrm{~m}$ downstream of the weir base. Measurements were undertaken for 10 flows ranging from 0.032 to $0.12 \mathrm{~m}^{3} \mathrm{~s}^{-1}$, increasing in equal intervals. Data was collected in the same manner for the different array arrangements. Stage-discharge relationships were determined using this data for each of the different treatments. Tests were undertaken when the array was mounted at a distance from the crest of $0.17,0.20,0.25,0.30,0.35$ and $0.40 \mathrm{~m}$. Velocities were measured for the configuration mounted $0.40 \mathrm{~m}$ from the crest. Four velocity measurements were taken along transects located immediately downstream of the last line of clusters, two directly in the wake of the clusters, and two in the middle laterally in between the clusters, $1.9 \mathrm{~m}$ downstream of the weir crest, using an electromagnetic open channel flow meter (Valeport Model 801). Average water depths were also measured at these locations and used to determine the Froude number. However, flow in the bristle section was highly turbulent and aerated and displayed large variations of depth in time and space. For this reason, although the values of averaged quantities are reported in this paper, these figures should be interpreted within the context of a very complex, two-phase flow. 


\section{Results}

\subsection{Laboratory fish passage trials}

Attempts varied between treatments being 45,43 and $38 \%$ for $\lambda b, \lambda c$ and $\lambda d$ respectively. Fish passage efficiency was higher for all treatments than the control (Table 2), under which movement was blocked. Passage efficiency did not differ between $\lambda \mathrm{b}, \lambda \mathrm{c}$ and $\lambda \mathrm{d}\left(\mathrm{X}^{2}=0.552, \mathrm{df}=2, p=0.75\right.$; Table 2). Time to pass (Fig. 3a) differed with CBC density $\left(\mathrm{X}^{2}=8.822, \mathrm{df}=2, p<0.05\right)$, being greater under $\lambda \mathrm{b}$ than $\lambda \mathrm{c}(p<0.05)$ and $\lambda \mathrm{d}(p<0.05)$ (Fig. 3a). There was no difference in time to pass between $\lambda \mathrm{c}$ and $\lambda \mathrm{d}(p=1.00$; Fig. 3a).

(a)

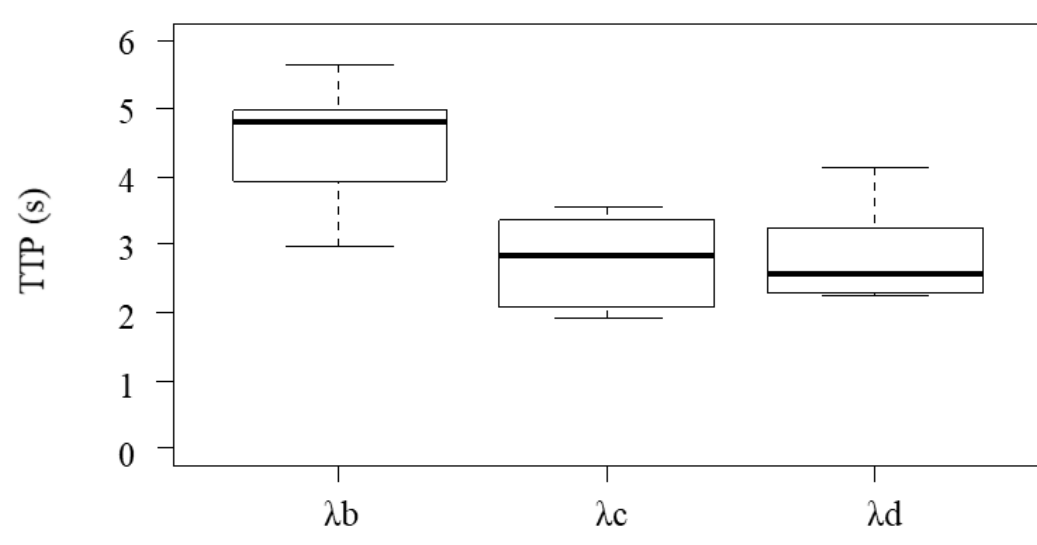

Density

(b)

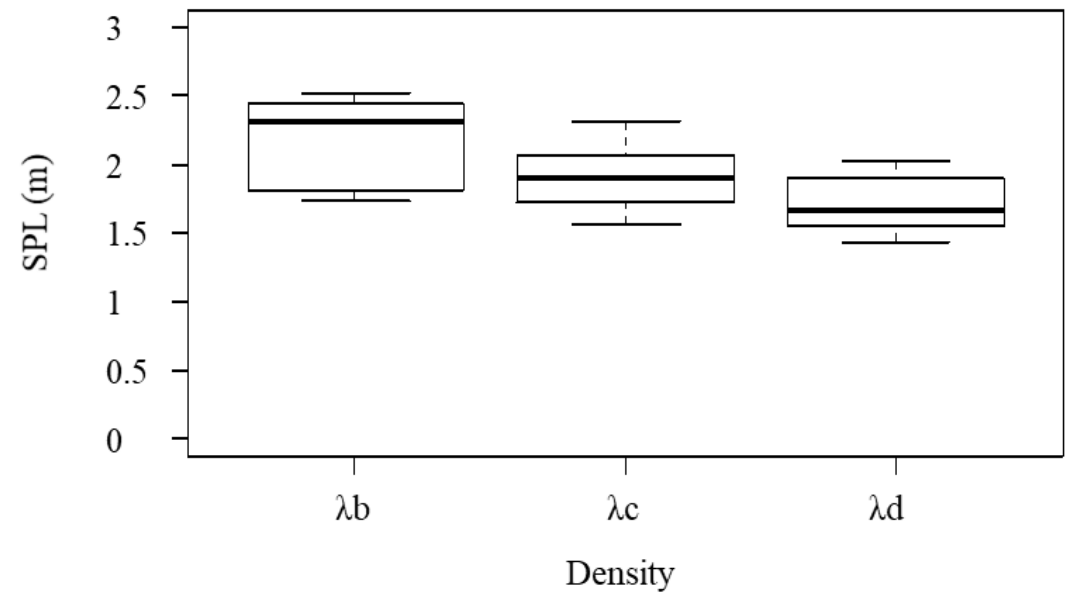

Fig.3 (a) Time to pass (TTP) for fish that passed over a Crump weir for treatments $\lambda b, \lambda c$ and $\lambda d$ where spacing between clusters was $0.06 \mathrm{~m}, 0.1 \mathrm{~m}$ and $0.15 \mathrm{~m}$, respectively; (b) Swim path length (SPL) (m) for $\lambda \mathrm{b}, \lambda \mathrm{c}$ and $\lambda \mathrm{d}$. Box plot of the median (horizontal line), interquartile range (box) and highest and lowest observations (whiskers). 
Table 2 Passage data showing the number of roach (Rutilus rutilus) that attempted, succeeded, and failed to pass over a Crump weir for the treatments tested in an open channel flume.

\begin{tabular}{|c|c|c|c|c|}
\hline Treatment & Pass & Fail & Attempts & Passage efficiency (\%) \\
\hline$\lambda \mathrm{a}($ Control) & 0 & 18 & 18 & 0 \\
\hline$\lambda \mathbf{b}\left(S_{d}=0.06\right)$ & 7 & 20 & 27 & 26 \\
\hline$\lambda c\left(S_{d}=0.10\right)$ & 7 & 19 & 26 & 27 \\
\hline$\lambda d\left(S_{d}=0.15\right)$ & 8 & 15 & 23 & 35 \\
\hline
\end{tabular}

As fish ascended the weir during treatments, they manoeuvred between CBCs within the array (Fig. 4). This occurred under all CBC densities and resulted in sinuous swim paths. Despite this common pattern of movement, swim path length (Fig. 3b) differed with CBC density $\left(X^{2}=6.674 \mathrm{df}=2, p<0.05\right)$, being longer under $\lambda b$ than $\lambda d$ $(\mathrm{p}<0.05)$ (Fig. 3b). Swim path length did not differ among other densities (Fig. 3b).

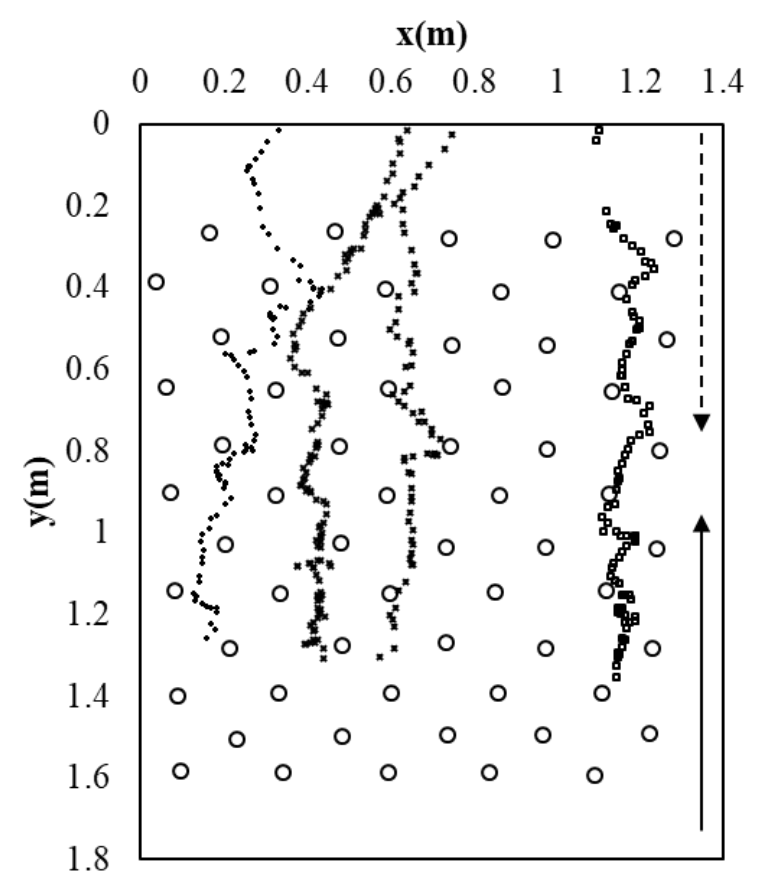

Fig.4 Examples of fish pathways over the weir through the staggered array of Cylindrical Bristle Clusters (circles) for $\lambda \mathrm{d}, 0$ denotes the location of the crest and 1.2 the base of the hydraulic jump, with $1.2 \mathrm{~m}$ in the y axis being the distance traversed up the weir and x coordinates denoting the weir width. Video analysis produced pathways created using fish tracking software where the position of the fish head during each frame was recorded. The dashed and solid arrows denote the flow and fish direction, respectively. 


\subsection{Field fish passage validation and debris monitoring}

Mean attraction efficiency did not differ when the fish pass was installed compared to the control (Table 3). Attraction was higher during the 2 weeks immediately after tagging and release under both the control and treatment periods.

Table 3 Detections of PIT tagged fish at loops located at the bottom (loop 1), middle (loop 2) and top (loop 3) of a Crump weir during treatment ( $\mathrm{T}$ : fish pass installed) and control (C: no fish pass installed) periods. Some of the fish detected during one control or treatment period may have been detected again during another period.

\section{Treatment Loop $1 \quad$ Loop 2 Loop $3 \quad \%$ Att $\quad$ Species numbers}

\begin{tabular}{|c|c|c|c|c|c|}
\hline C1 & 31 & NA & 0 & 18.8 & 14 roach, 6 chub, 4 eel, 3 dace, 3 perch, 1 gudgeon \\
\hline $\mathbf{T 1}$ & 20 & NA & 0 & 12.1 & 11 roach, 3 perch, 2 chub, 2 dace, 1 gudgeon, 1 pike \\
\hline $\mathrm{C2}$ & 24 & 0 & 0 & 14.5 & 12 roach, 4 chub, 4 perch, 1 dace, 1 eel, 1 gudgeon, 1 pike \\
\hline $\mathbf{T} 2$ & 68 & 23 & 10 & 23 & $\begin{array}{l}31 \text { roach, } 18 \text { chub, } 7 \text { perch, } 4 \text { bream, } 3 \text { eel, } 2 \text { dace, } 1 \\
\text { gudgeon, } 1 \text { pike, } 1 \text { rudd }\end{array}$ \\
\hline $\mathbf{C 3}$ & 10 & 2 & 1 & 3.5 & 5 roach, 3 perch, 1 eel, 1 pike \\
\hline T3 & 22 & 8 & 2 & 7.8 & 13 roach, 5 perch, 2 chub, 1 eel, 1 bream \\
\hline
\end{tabular}

A range of fish species and sizes attempted to pass the weir in the field during both control and treatment periods (Table 3). Roach (length $=0.12 \mathrm{~m} \pm 0.012 \mathrm{~m}$ ), perch (length $=0.18 \pm 0.024)$, eel (length $=0.33 \mathrm{~m})$, pike (length $=0.60 \mathrm{~m}$ ) and chub (length $=0.22 \pm 0.099)$ were detected at the middle loop, representing $30 \%$ of those that were detected at the base of the weir.

When data for all species was aggregated, passage efficiency was $14 \%$ and $2 \%$ during treatment and control periods, respectively. One pike $(0.60 \mathrm{~m})$ passed over the weir during the control. Chub were the only species that passed the weir when the fish pass was installed, achieving a passage efficiency of 52\%. No other species successfully passed the weir.

Despite experiencing similar discharge regimes $\left(0.39 \pm 0.37 \mathrm{~m}^{3} \mathrm{~s}^{-1}\right.$ and $0.49 \pm 0.7 \mathrm{~m}^{3} \mathrm{~s}^{-1}$ for the control and treatment periods, respectively) chub attempted to pass under a greater range of flows when the pass was installed 
(range $=0.29-5.56 \mathrm{~m}^{3} \mathrm{~s}^{-1}$ with mean $\pm \mathrm{SD}=2.56 \pm 1.50 \mathrm{~m}^{3} \mathrm{~s}^{-1}$ ) compared to the control (range $=0.29-$ $0.50 \mathrm{~m}^{3} \mathrm{~s}^{-1}$ with mean $\pm \mathrm{SD}=0.39 \pm 0.07 \mathrm{~m}^{3} \mathrm{~s}^{-1}$ ) with all bar one of those that passed doing so below the $10 \%$ exceedance flow (i.e. values of $\mathrm{Q}$ that were exceeded for $10 \%$ of the study period) (range $=0.40-4.31 \mathrm{~m}^{3} \mathrm{~s}^{-}$

${ }^{-1}$ with mean $\pm \mathrm{SD}=2.18 \pm 0.99 \mathrm{~m}^{3} \mathrm{~s}^{-1}$ ).

Although all chub passed when the CBCs were installed, the best performing binomial logistic regression model was where length (coeff: $1.076 \mathrm{e}-02 \pm \mathrm{SE} 5.488 \mathrm{e}-03, p<0.05$ ) and fish pass installation (coeff: $1.957 \mathrm{e}+01 \pm \mathrm{SE}$ $3.600 \mathrm{e}+03, p=0.996$ ) were considered in combination. The mean $\pm \mathrm{SD}$ fish length of those that passed was $0.37 \pm 0.09 \mathrm{~m}$ compared to $0.22 \pm 0.12 \mathrm{~m}$ for those that attempted and failed.

\subsection{Effect on gauging}

Rating curves were obtained for the unmodified and retrofitted weir (Fig. 5) collating data from separate tests in which the $\mathrm{CBCs}$ were positioned at distances of $0.2,0.3$ and $0.4 \mathrm{~m}$ downstream of the crest $(5 \mathrm{a}, 5 \mathrm{~b}, 5 \mathrm{c}$, respectively). When the CBCs were placed close to the crest, flow gauging was affected over a wide range of discharges (Fig. 5a). The difference between stage discharge curves was observed to increase with the density of the cluster (i.e., in $5 \mathrm{a} \lambda \mathrm{A}$ deviates more from $\lambda \mathrm{C}$ than $\lambda \mathrm{B}$ ), as expected from the higher energy losses produced by the denser cluster. However, as the array is moved farther from the crest the extent of the impact on gauging is considerably reduced, only being significant for the higher range of discharges (Fig. 5b). At $0.4 \mathrm{~m}$ from the crest ( Fig. 5c), none of the configurations tested affected gauging significantly (i.e. maximum difference in the measured water depth between treatment and control was $<3 \%$ of the control water depth). $\lambda \mathrm{A}, \lambda \mathrm{B}$ and $\lambda \mathrm{C}$ reduced water velocities immediately downstream of the last line of clusters farthest away from the crest on average by 51, 35 and $29 \%$ compared to the control. Froude numbers in this location indicated that flow was supercritical under all treatments and discharge regimes (minimum observed was $\mathrm{Fr}=1.3$ ). 
(a)

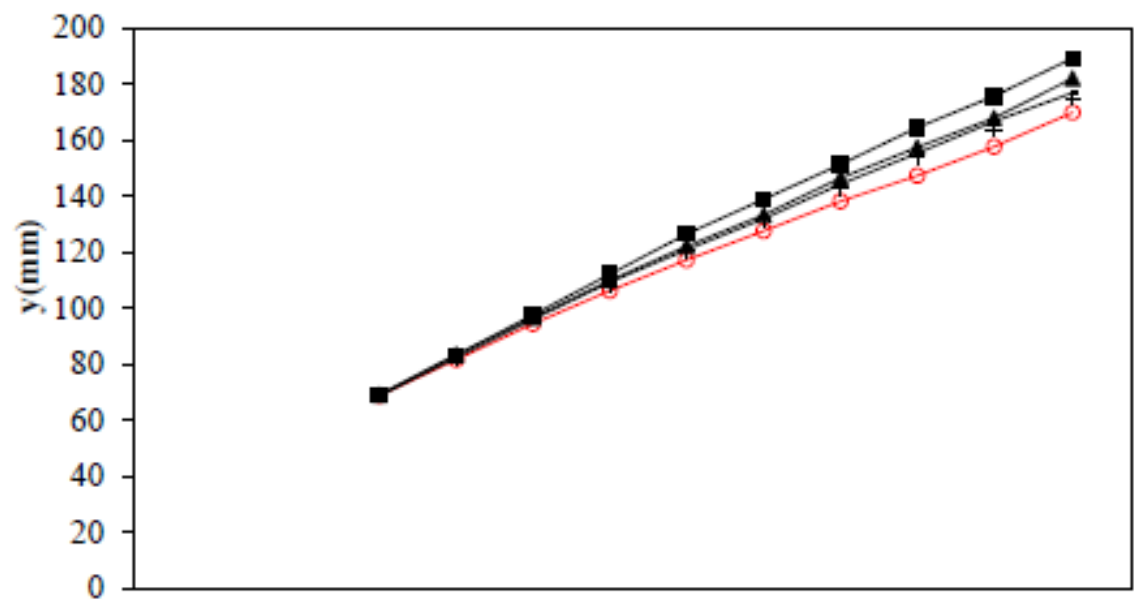

(b)

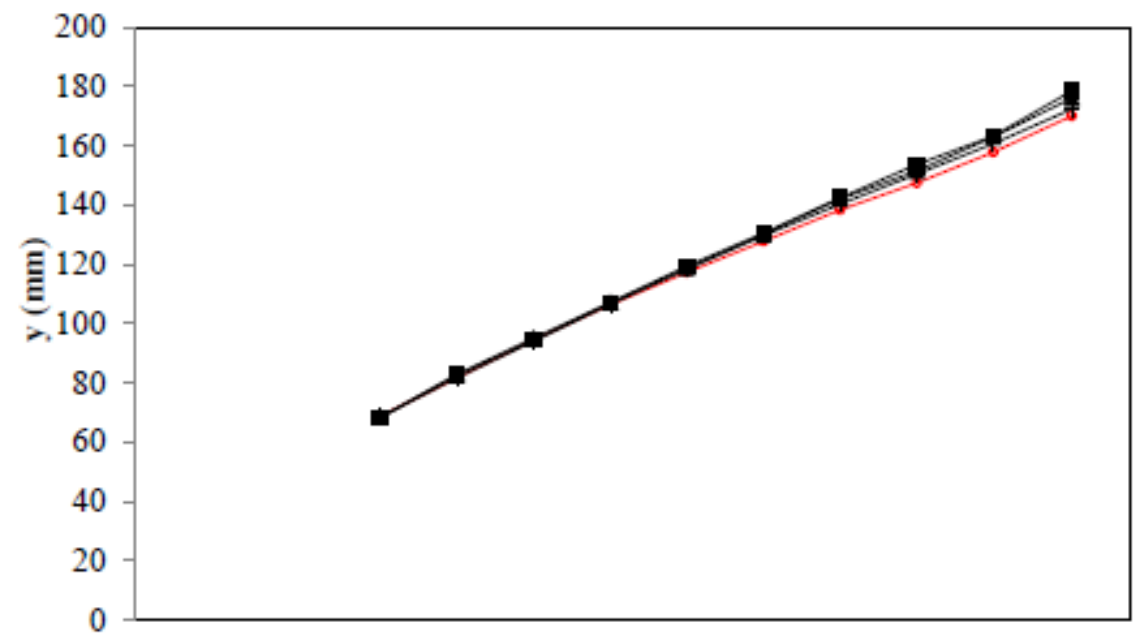

(c)

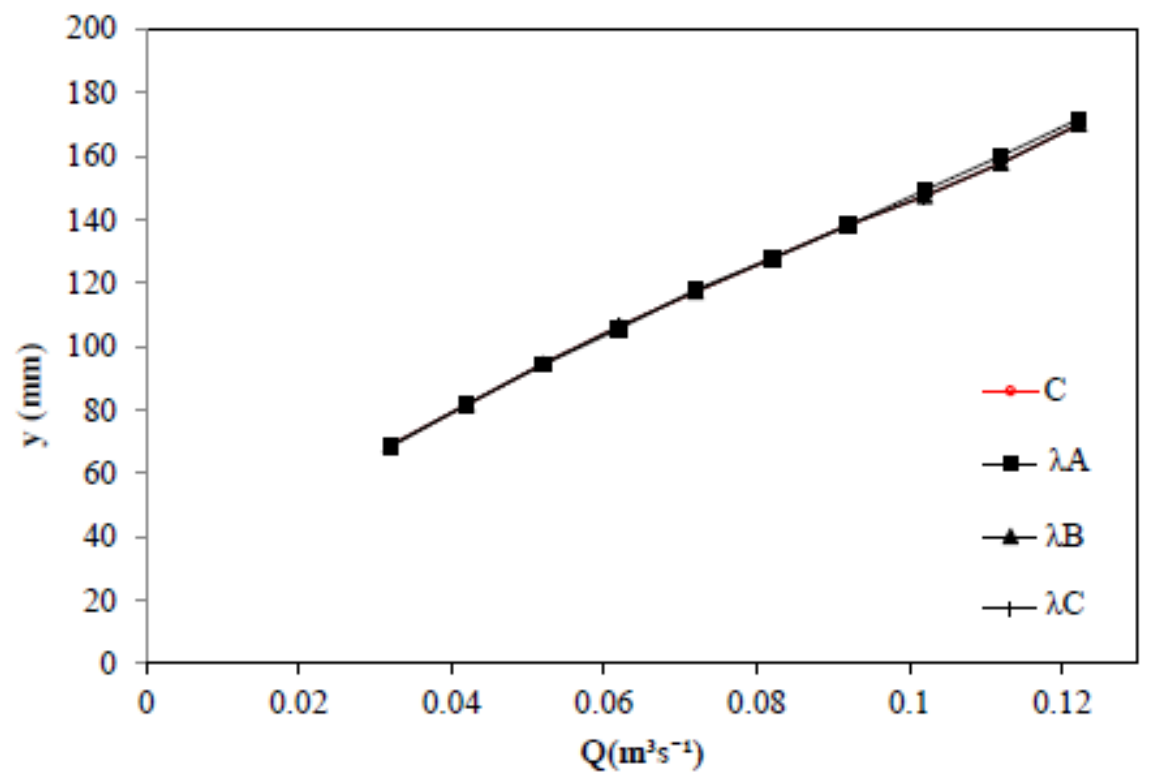

Fig.5 Stage-discharge relationship for the control and treatments $0.07 \mathrm{~m}$ diameter with $0.1(\lambda \mathrm{A})$ and $0.15(\lambda \mathrm{B})$ $\mathrm{m}$ diagonal spacing and $0.05 \mathrm{~m}$ diameter with $0.15 \mathrm{~m}$ diagonal spacing $(\lambda \mathrm{C})$ at (a) 0.2 , (b) 0.3 and (c) $0.4 \mathrm{~m}$ from the crest. 


\section{Discussion}

\subsection{Laboratory fish passage trials}

The passage efficiency for roach at an unmodified model Crump weir in an open channel flume was $0 \%$. Only two fish progressed past the hydraulic jump, a region characterised by high levels of aeration and turbulence which likely increased energetic cost of swimming (Enders et al., 2003) and destabilised fish (Tritico and Cotel, 2010). For those that did progress beyond the hydraulic jump, passage was impeded by high water velocity (max $\left.2.5 \mathrm{~m} \mathrm{~s}^{-1}\right)$.

The passage efficiency for roach improved to approx. 30\% when CBCs were installed on the downstream face of the weir. Passage was likely facilitated by fish utilising low velocity zones/shear in the wake of CBCs and/or because bulk velocity decreased. Indeed, the sinuous paths taken as the fish navigated the weir highlighted the importance of the hydrodynamic heterogeneity created due to the provision of low velocity zones in the wake of the clusters. Future designs may be adjusted to maximise the length of the low velocity zone behind the CBCs to further improve fish passage.

Passage efficiencies did not differ between the high $(\lambda b)$, medium $(\lambda c)$ and low $(\lambda d)$ density arrays tested, possibly because the mean water velocities were similar between the treatments, and/or the space available was not sufficiently different to affect manoeuvrability. Any of the configurations tested when placed on a gauging weir would be sufficient to improve passage efficiency provided the water velocity remained below the maximum burst speed for the subject fish. For this to be the case over a large range of flows, a higher hydraulic resistance created by the clusters would be required to prevent the velocity through the bristles increasing (as for sparse vegetation arrangement; Nepf, 2012) to a point at which fish passage was prevented. This could, however, have a potential negative impact on gauging accuracy. To prevent this, alternative configurations that continue to enable fish to utilise the heterogeneous hydrodynamic environment created by the clusters while maintaining gauging efficiency over a wider range of flows should be investigated. It is possible that increased cluster diameter would have greater benefit for passage as the larger wakes and wake overlap created may increase the area available for fish to rest.

The time taken to pass the weir was shorter when cluster density was low. This was a function of the ratio of cluster spacing to body length, which can be approximated by understanding that the distance travelled by a fish per tail beat is greater for a larger tail amplitude (Bainbridge, 1957). Greater passage would be expected if manoeuvrability was not hampered because fish could swim farther for the same number of tail beats, reducing passage time. Alternatively, when cluster spacing was smaller, time to pass would increase as fish adopt more tortuous paths to navigate denser clusters to progress upstream. 
There was no difference in time to pass between the two lowest density treatments ( $\lambda \mathrm{c}$ and $\lambda \mathrm{d}$ ). This suggested neither treatments constrained fish movement and that both spacings were sufficient to facilitate passage without hampering manoeuvrability. Similarly, the lack of difference in swim path length between $\lambda \mathrm{c}$ and $\lambda d$ indicated that spacing was not a constraint for the size of fish tested. The variation in swim path length between $\lambda b$ and $\lambda d$ could also be attributed to spacing constraints as, for the fish tested, the body amplitude would need to be between 0.02 and $0.07 \mathrm{~m}$ for swimming to remain uninhibited (Bainbridge, 1957). Fish movement would become increasingly inhibited as swim path length increases when fish must manoeuvre around the clusters to successfully navigate the array.

\subsection{Field fish passage validation and debris monitoring}

When fish passage was assessed in the field, a Crump weir was observed to pose a barrier to upstream fish movements. The installation of CBCs enabled some fish to ascend the weir, but overall efficiency remained low (14\%). Under the control, passage was likely limited by a combination of factors, including a relatively long weir face $(7 \mathrm{~m})$, high velocity and shallow depth. Such conditions have previously been shown to limit the passage of non-salmonids (barbel and grayling) (Lucas and Frear, 1997; Lucas and Bubb, 2005) with similar swim speeds to chub that attempted to pass the weir in this study.

Chub approached under a greater range of flows when the fish pass was installed compared to the control $(0.238-$ 5.56 and $0.238-0.499$ ). This may be explained by more favourable approach conditions being formed at the base of the weir when the clusters reduced the bulk velocity, resulting in a reduction in the magnitude of the hydraulic jump (Chadwick et al., 2004), and less turbulence and aeration (Resch and Leutheusser, 1972) as a result. In agreement with the observation of others (e.g. Forty et al., 2016), attraction efficiency under both control and treatment conditions was highest immediately after the release of tagged fish.

Overall, $73 \%$ of fish did not attempt to ascend the weir, possibly indicating a lack of motivation to move upstream and/or sufficient availability of suitable habitat downstream. However, a range of species (bream, perch, gudgeon, rudd, roach, dace, perch, eel, pike and chub) attempted to ascend the weir (i.e. detected at the downstream and middle PIT loop), with some individuals attempting to pass multiple times, resulting in successful passage for only a limited number of chub and pike. This suggested that, even with the installation of $\mathrm{CBCs}$, this weir remained a significant barrier to most species, and partial barrier to others. This indicates that the suitability of the design tested is variable, providing a feasible solution for low head weirs, but becoming increasingly limited for higher head structures. Further design optimisation and monitoring of field installations is needed to understand design limitations, and decisions to employ this fish passage solution will depend on the specific goals set. 
Passage of chub was influenced by fish length (mean \pm SD of those that passed was $0.37 \pm 0.09 \mathrm{~m}$ compared to $0.22 \pm 0.12 \mathrm{~m}$ for those that attempted and failed). Swimming performance is known to be positively related to fish size, so it was expected that larger chub were more likely to pass the modified structured provided there was sufficient room between the clusters to manoeuvre. All chub that passed did so when the CBCs were installed, although this finding was limited by the availability of data, with only 4 fish attempting to do so under the control compared to 21 during the treatment. Here, an attempt was classified as the last attempt (if not successful) or the attempt immediately prior to the first successful passage, irrespective of treatment, as for the statistical analysis, avoiding violation of the assumptions required for statistical analysis i.e. "repeat measures". Passage occurred under relatively high flows, but while the weir remained unsubmerged. Under the highest flows, the hydraulic jump was raised to the middle loop reducing the distance fish had to traverse the barrier from $7 \mathrm{~m}$ to $3 \mathrm{~m}$.

Although passage efficiency was 52\% for chub, two fish were detected moving back downstream within $30 \mathrm{~s}$ of passing the weir. These may have been volitional movements or could have resulted from fatigue and associated fallback. If the latter, it would imply that the fish pass requires modification so that water velocities are further reduced, and/or more effective resting areas are provided at the top of the pass to enable recovery.

Only $30 \%$ of the roach that attempted reached the middle of the weir and none successfully passed the crest. It is possible that the weir was excessively long to allow passage for this species, as burst swimming through the arrays can only be maintained for short periods of time (Knaepkens et al., 2007). Even if the water velocity was below the maximum burst swimming speed, passage would have been unsuccessful if the fish fatigued before reaching the weir crest. Therefore, metrics such as distance of ascent (Castro-Santos et al., 2009) in addition to burst swimming capability should be considered when developing design criteria. For longer weirs, a fish must either increase its swim speed to pass before fatigue or maintain the same speed for longer. The difficulty in balancing swim speed, distance of ascent, and time to fatigue remains an important challenge in fish passage design, and better understanding of this interaction between the factors requires further research.

\subsection{Effect on gauging}

The effect of CBCs on the gauging accuracy of a model Crump weir in an open channel flume was greatest when the array density and flow was highest and installed close to the crest. CBC arrays respectively increase and decrease water depth and velocity on the downstream weir face. When this occurred close to the crest, the hydrodynamic alterations caused by the CBC array likely propagated upstream, presumably impeding the transition from sub- to supercritical flow through the point of critical depth (Rickard et al., 2003). The extent of any impacts on gauging will depend on the backwater effect created by the clusters. As the exact location where critical depth occurs is difficult to predict, so too is the precise location that CBC arrays can be placed without impacting gauging. When CBC arrays were placed $0.4 \mathrm{~m}$ from the weir crest, gauging accuracy did not differ between any of the densities tested and the control (unmodified weir). This is because a zone is maintained between the crest and cluster array where flow can transition from sub- to supercritical. Being able to place CBC 
arrays relatively close to the crest of gauging weirs without compromising hydrometric standards provides a potential advantage over alternative (baffled) designs in some cases as they create a greater blockage to flow and consequently a greater backwater effect. 


\section{Conclusions}

Fish utilised a staggered array of Cylindrical Bristle Clusters (CBCs) to surmount a Crump gauging weir; passage efficiency improved from 0 to $30 \%$ for roach under experimental conditions, and from 0 to $52 \%$ for chub in the field. Under experimental conditions, lower array densities provided greater space for fish to manoeuvre to regions of low velocity in the wake of clusters, reducing swim path length during ascents and the time taken to pass. Further design optimisation may be achieved by increasing the cluster diameter to increase wake width and length, thus providing a greater proportion of low velocity areas that fish utilise during weir passage.

Gauging accuracy of the modified Crump weir will not be compromised if a zone is maintained between the crest and cluster array where flow can transition from sub- to supercritical. The length of this "buffer zone" in which supercritical flow is achieved is dependent on array density and discharge. A buffer zone with a maximum distance of $0.4 \mathrm{~m}$ between the crest and the most upstream line of bristles did not impact gauging under the highest array density and discharge tested, with upstream water depth remaining uninfluenced by downstream flow disturbance. Placement of clusters close to the weir crest without compromising gauging accuracy is a key benefit of this design for regulatory agencies, ecological engineers, and the operators and managers of river infrastructure tasked with mitigating habitat fragmentation for fish while maintaining the provision of services. The simplicity and modularity of a staggered array of CBCs also is a key benefit of this design, improving cost effectiveness and ease of installation. Due to the widespread occurrence of gauging weirs and other similar low head structures in the world's rivers, this novel low-cost multispecies fish passage solution is likely to generate significant benefits for fish conservation and fisheries restoration.

\section{Acknowledgments}

The research leading to these results has received funding from the Engineering and Physical Sciences Research Council (EPSRC), UK, grant reference: EP/L01582X/1 and the Environment Agency, UK, grant reference: 16997/01. We thank Toru Tsuzaki, Ashley Rogers, Anita Laborde, Perikles Karageorgopoulos, Robert Needham, David Gilbert, the ICER team and all volunteers that helped during fieldwork for their technical assistance during experimental periods.

\section{Declaration of competing interest}

The authors declare that they have no known competing financial interests or personal relationships that could have appeared to influence the work reported in this paper. 


\section{References}

Armstrong, G.S., Aprahamian, M.W., Fewings, A.G., Gough, P.J., Reader, N.A., Varallo, P.V., 2010. Environme nt Agency Fish Pass Manual. Environment Agency.

Bainbridge, R., 1957. The Speed of Swimming of Fish as Related to Size and to the Frequency and Amplitude of the Tail Beat. The Zoological Laboratory, Cambridge, p. 109.

Baker, C.F., Boubée, J.A., 2006. Upstream passage of inanga Galaxias maculatus and redfin bullies Gobiomorphus huttoni over artificial ramps. J. Fish Biol. 69, 668-681. doi:10.1111/j.1095-8649.2006.01138.x.

BS ISO 4360:2008, 2008. Hydrometry-Open Channel Flow Measurement Using Triangular Profile Weirs. BSI.

Castro-Santos, T., Cotel, A., Webb, P.W., 2009. Fishway Evaluations for Better Bioengineering - An Integrative Approach.

Chadwick, A., Morfett, J., Brothwick, M., 2004. Hydraulics in Civil and Environmental Engineering. 4th ed. Spon Press, London.

Clough, S.C., Turnpenny, A.W.H., 2001. Swimming Speeds in Fish: Phase 1. Environment Agency.

Dibley, M., Child, S., Iredale, R., Wiggins, A., 2012. Fish and Flow - Maintaining the Balance Between Hydrometric Uncertainty and Aids to Fish Passage at Flow Gauging Structures. 01-05.

Dodd, J.R., Cowx, I.G., Bolland, J.D., 2018. Win, win, win: low cost baffle fish pass provides improved passage efficiency, reduced passage time and broadened passage flows over a low-head weir. Ecol. Eng. 120, 68-75. doi:10.1016/j.ecoleng.2018.05.028.

Enders, E.C., Boisclair, D., Roy, A.G., 2003. The effect of turbulence on the cost of swimming for juvenile Atlantic salmon (Salmo salar). Can. J. Fish. Aquat. Sci. 60 (9), 1149-1160.

Forty, M., Spees, J., Lucas, M.C., 2016. Not just for adults! Evaluating the performance of multiple fish passage designs at low-head barriers for the upstream movement of juvenile and adult trout Salmo trutta. Ecol. Eng. 94, 214-224.

Kerr, J.R., Karageorgopoulos, P., Kemp, P.S., 2015. Efficacy of a side-mounted vertically oriented bristle pass for improving upstream passage of European eel (Anguilla anguilla) and river lamprey (Lampetra fluviatilis) at an experimental Crump weir. Ecol. Eng. 85, 121-131. 
Kerr, J.R., Manes, C., Kemp, P.S., 2016. Assessing hydrodynamic space use of brown trout, Salmo trutta, in a complex flow environment: a return to first principles. J. Exp. Biol. 219 (Pt 21), 3480-3491.

Knaepkens, Maerten, Eens, 2007. Performance of a pool-and-weir fish pass for small bottom-dwelling freshwater fish species in a regulated lowland river. Animal Biology 57 (4), 423-432.

Larinier, M., 2001. Dams, fish and fisheries opportunities, challenges and conflict resolution. In: Marmulla, G. (Ed.), Environmental Issues, Dams and Fish Migration.

Lucas, M.C., Baras, E., 2001. Migration of Freshwater Fishes. Blackwell Science, Oxford.

Lucas, M.C., Bubb, D.H., 2005. Seasonal Movements and the Habitat Use of Grayling in the UK. Environment Agency Science Report SC030210/SR. Environment Agency, Bristol.

Lucas, M.C., Frear, P.A., 1997. Effects of a flow-gauging weir on the migratory behaviour of adult barbel, a riverine cyprinid. J. Fish Biol. 50, 14.

Nepf, H.M., 2012. Hydrodynamics of vegetated channels. J. Hydraul. Res. 50 (3), 262-279. doi:10.1080/00221686.2012.696559.

Nicolle, A., 2009. Flow Through and Around Groups of Bodies. PhD Thesis. University College London.

Pringle, C.M., 2001. Hydrologic connectivity and the management of biological reserves: a global perspective. Ecol. Appl. 11, 981-998.

Resch, F.J., Leutheusser, H.J., 1972. Le ressaut hydraulique: mesure de turbulence dans la re 'gion diphasique [The hydraulic jump: turbulence measurements in the two-phase flow region]. J. La Houille Blanche 4, 279293. (in French).

Rickard, C., Day, R., Purseglove, J., 2003. River Weirs - Good Practice Guide. Environment Agency.

Russon, I.J., Kemp, P.S., Lucas, M.C., 2011. Gauging weirs impede the upstream migration of adult river lamprey Lampetra fluviatilis. Fish. Manag. Ecol. 18 (3), 201-210.

Servais, S.A., 2006. Physical Modelling of Low-Cost Modifications to the Crump Weir in Order to Improve Fish Passage: Development of Favourable Swimming Conditions and Investigation of the Hydrometric Effect. (Cranfield).

Taddei, S., Manes, C., Ganapathisubramani, B., 2016. Characterisation of drag and wake properties of canopy patches immersed in turbulent boundary layers. J. Fluid Mech. 798, 27-49. 
Tritico, H.M., Cotel, A.J., 2010. The effects of turbulent eddies on the stability and critical swimming speed of creek chub (Semotilus atromaculatus). J. Exp. Biol. 213 (Pt 13), 2284-2293.

Tummers, J.S., Kerr, J., O’Brien, P., Kemp, P., Lucas, M.C., 2018. Enhancing the upstream passage of river lamprey at a microhydropower installation using horizontally-mounted studded tiles. Ecol. Eng. 125, 87-97. doi:10.1016/j.ecoleng.2018.10.015.

Vörösmarty, C.J., McIntyre, P.B., Gessner, M.O., Dudgeon, D., Prusevich, A., Green, P., Glidden, S., Bunn, S.E., Sullivan, C.A., Liermann, C.R., 2010. Global threats to human water security and river biodiversity. Nature 467, 555-561.

Vowles, A.S., Don, A.M., Karageorgopoulos, P., Worthington, T.A., Kemp, P.S., 2015. Efficiency of a dual density studded fish pass designed to mitigate for impeded upstream passage of juvenile European eels (Anguilla anguilla) at a model Crump weir. Fish. Manag. Ecol. 22 (4), 307-316.

Vowles, A.S., Don, A.M., Karageorgopoulos, P., Kemp, P.S., 2017. Passage of European eel and river lamprey at a model weir provisioned with studded tiles, J. Ecohydraulics, 2:2, 88-98, DOI: 10.1080/24705357.2017.1310001

Wang, X.K., Gong, K., Liu, H., Zhang, J.-X., Tan, S.K., 2013. Flow around four cylinders arranged in a square configuration. J. Fluid. Struct. 43 (21).

Watz, J., Nilsson, P.A., Degerman, E., Tamario, C., Calles, O., 2019. Climbing the ladder: an evaluation of three different anguillid eel climbing substrata and placement of upstream passage solutions at migration barriers. Anim. Conserv. doi:10.1111/acv.12485.

Wessels and Rooseboom, 2009. Flow-gauging structures in South African rivers part 1: an overview. Water SA 35 (1). 